\title{
Intrusiveness in professional and world tour road cycling: the "Troy horse" playing the role of coaches, head of performance, or sport science professionals
}

\author{
Mikel Zabala ${ }^{1}$ \\ * Correspondence: (MZ) mikelz@ugr.es \\ Published: 30 December 2021
}

1 Faculty of Sport Science, University of Granada, Spain

Cycling is nowadays much better considered than one or two decades ago, after all the doping scandals reached their highest level with Lance Armstrong case (Zabala, 2017). This was called a necessary tsunami that would hurt both some good things but also and mainly really bad things like the doping culture. But before "Armstrong" case, we found "Festina" case in 1998 and later "Puerto" case in Spain in 2006. As Morente-Sánchez and Zabala (2013) pointed out, "Puerto" case was an inflection point in terms of letting all the people know (from cycling world to spectators, sponsors etc) that doping culture was taken as a shame, worse that just cheating. So, the rules were clear for everybody. Then antidoping rules and actions were strictly applied: Whereabouts, biological passport, "no needle policy"... and the creation of organizations as "Movement for a credible cycling" or "Clean cycling" to which different world tour and pro teams were affiliated (not all of them because self-obliged restrictions were sometimes hard to achieve or so believed some managers of important cycling teams).

After many years of public punishment, and after suffering "Armstrong" case, cycling seemed to learn from its own mistakes (Morente-Sánchez and Zabala, 2014). Of course, other sports were not "angels", but cycling was the most exposed sport of all of them. "Fancy bear" hackers club revealed different cases of doping among numerous sports like athletics, gymnastics, football... and a shameful use of the Therapeutic Use Exemption (TUE) politics in favour of very famous and outstanding athletes. Then more actions like banning substances like Tramadol were driven, even if science still suggests that this is not a problem for athletes nowadays as it does not affect negatively cognitive processes and so it cannot be assumed that it could create massive crashes in the peloton (Zandonai et al., 2021), as it is wrongly suggested by some badly documented journalists. Anyway, the most important action was taken by the International Cycling Union (UCI) when they forced the world tour teams to contract coaches and specifically banning doctors to play a role as coaches or being related to the training process. This was called "organizational criterion", and all the world tour teams must achieve this criterion (as for example the economical criteria) so they could get or maintain the world tour licence (Zabala, 2017).

We are not here to talk about this dark past that, by the way, we must know to never forget. We are here to recognize the positive steps that were made, and also to warn about the "Troy horse" that could spoil all these positive advances: this is the attitude that boosted cheating culture in the past that, may be arising again using a different shape. Yes, we are warning about those people that were cheaters in the past and are trying to cheat 
nowadays. Those are mainly ex-cyclist who were sanctioned for doping and nowadays without the appropriate formation and studies are involved in pro or world tour teams, as well as coaching pro cyclists individually. Also, there are some coaches that are not prepared for such a job, but they are good friends of someone that decides in the team, or pseudo -nutritionist, biomechanics... and it is said that some banned professionals involved in "Armstrong" case are still coaching in the shadow professional riders.

We could "speak louder" but we could not "speak more clearly". There are different kind of cheaters: those that were objectively dopers-cheaters in the past that are now playing a professional role to which they are not accredited, and those that are just cheating nowadays playing their professional role without the appropriate tittle. We must stand out those that do not own a sport science degree to play the role of a coach for professional athletes or, more obviously, to play the role of a "head of performance" or "sport scientist". Also, for example, those that work as nutritionists not owning the specific tittle to be working on such a role. Can anyone imagine a doctor with no tittle working in any institution or company? What a paradox! Doctors in the team are banned to take part in cyclists' training process but someone with no preparation can do it.

Maybe the most important aim of this journal is to boost science to be a practical and useful part of professional sport, appealing to the "2.0 cycling": the integrative, fair and transparent cycling. This was the first editorial of the Journal of science and cycling 10 years ago in 2012 when the journal was launched (Zabala and Atkinson, 2012). Many things have been improved since then, so that we are convinced that cycling is nowadays the cleaner elite sport in the world. But we cannot get slept, we must seek for the highest standards not just for the elite cycling but also for the amateur (Zabala et al., 2016; Fincoeur et al., 2020). Then, we must recognize the "Troy horse" so we can fight it properly. More responsibility and more ethics maybe from those that make the contracts not asking for the necessary tittle? Yes, may be the intruders exist because some managers and CEOs allow them this existence. So let's be cautious... Troy was conquered, and professional road cycling could be seriously injured again.

\section{References}

1. Fincoeur, B., Gleaves, J. \& Ohl, F. (2020). Doping in cycling: Interdisciplinary perspectives. Routledge, London (UK).

2. Morente-Sánchez, J. \& Zabala, M. (2013). Doping in Sport: A Review of Elite Athletes' Attitudes, Beliefs and Knowledge. Sports Medicine. 43(6): 395-411.

3. Morente-Sánchez, J., \& Zabala, M. (2014). Spanish cycling and attitudes towards doping of different stakeholders involved. Journal of Science and Cycling, 3(1), 21-25. Retrieved from https://jscjournal.com/index.php/JSC/article/view/82

4. Zabala, M., \& Atkinson, G. (2012). Looking for the "Athlete 2.0": a collaborative challenge. Journal of Science and Cycling, $1(1), \quad 1-2$. Retrieved from https://jscjournal.com/index.php/JSC/article/view/17

5. Zabala, M., Morente-Sánchez, J., MateoMarch, M. \& Sanabria, D. (2016). Relationship between Self-Reported Doping Behavior and Psychosocial Factors in Adult Amateur Cyclists. Sport Psychologist, 30(1), 68-75.

6. Zabala, M. (2017). Doping's dark past and a new cycling era. In: Cheung, S.S., and Zabala, M. (2017) Cycling Science. Human Kinetics, Champign, Illinois. 220-232.

7. Zandonai, T., Holgado, D., Ciria, L.F., Zabala, M., Hopker, J., Bekinschtein, T. \& Sanabria, D. (2021). Novel evidence on the effect of Tramadol on self-paced highintensity cycling. Journal of Sports Sciences. 39(13): 1452-1460. 